DOSSIÊ TEMÁTICO: Educação, currículo e juventudes: dilemas e desafios atuais

do1 https://doi.org/10.22481/praxisedu.v16i42.7347

\title{
TRAJETÓRIAS DE FORMAÇÃO DA JUVENTUE TRABALHADORA BRASILEIRA: DAS PROMESSAS ÀS INCERTEZAS
}

\author{
TRAINING TRAJECTORIES OF YOUNG BRAZILIAN WORKERS: FROM PROMISES
}

TO UNCERTAINTIES

\author{
TRAYECTORIAS DE FORMACIÓN DE LOS JÓVENES TRABAJADORES \\ BRASILEÑOS: DE LAS PROMESAS A LAS INCERTIDUMBRES
}

\author{
José Humberto da Silva \\ Universidade do Estado da Bahia - Brasil \\ Liliana Rolfsen Petrilli Segnini \\ Universidade Estadual de Campinas - Brasil
}

\begin{abstract}
Resumo: O presente artigo analisa os investimentos pessoais e financeiros, bem como os arranjos construídos pelos jovens, desde a educação básica ao ensino superior, na perspectiva da garantia do acesso ao emprego e, por conseguinte, uma mudança de posição na estrutura social vigente. $\mathrm{O}$ caminho metodológico adotado aglutinou método, técnicas e instrumentos de pesquisa numa abordagem que articula dados quantitativos (acompanhamento das trajetórias in loco) e qualitativos, a partir de diferentes fontes de dados que informam dados educacionais e de emprego no Brasil. Os primeiros investimentos e arranjos realizados, na perspectiva da obtenção deste emprego, foram centrados nos esforços para que esses jovens conseguissem a conclusão do ensino médio, em seguida os cursos de qualificação profissional e, por fim, o acesso ao ensino superior privado. A relação entre trabalho e educação ganha centralidade nas trajetórias pesquisadas. Por meio dos percursos analisados, constatou-se que há um forte discurso em favor da educação como sendo, se não a única, a principal estratégia de mobilidade social ascendente.
\end{abstract}

Palavras-chave. Juventude, Processos formativos, Trabalho.

Abstract: This article analyzes the personal and financial investments, as well as the agreements made by young people, from basic education to higher education, in order to guarantee access to employment and, consequently, a change of position in the current social structure. The methodological path adopted brought together research methods, techniques and instruments in an approach that articulates quantitative data (monitoring of trajectories in loco) and qualitative data, from different data sources that inform educational and labor data in Brazil. The first investments and arrangements made to obtain this job focused on the efforts of these young people to complete secondary school, followed by professional qualification courses and, finally, access to private higher education. The relationship between work and education occupies a central place in the trajectories 
investigated. Through the routes analyzed, it was found that there is a strong discourse in favor of education as if be, if not the only, the main strategy of upward social mobility.

Keywords: Youth. Formative processes. Job.

Resumen: Este artículo analiza las inversiones personales y financieras, así como los acuerdos construidos por los jóvenes, desde la educación básica hasta la educación superior, con el fin de garantizar el acceso al empleo y, en consecuencia, un cambio de posición en la estructura social actual. La ruta metodológica adoptada reunió métodos, técnicas e instrumentos de investigación en un enfoque que articula datos cuantitativos (monitoreo de trayectorias in loco) y cualitativos, de diferentes fuentes de datos que informan los datos educativos y laborales en Brasil. Las primeras inversiones y arreglos realizados, con miras a obtener este trabajo, se centraron en los esfuerzos de estos jóvenes para completar la escuela secundaria, seguidos de cursos de calificación profesional y, finalmente, el acceso a la educación superior privada. La relación entre trabajo y educación ocupa un lugar central en las trayectorias investigadas. A través de las rutas analizadas, se encontró que existe un fuerte discurso a favor de la educación como, si no la única, la principal estrategia de movilidad social ascendente.

Palabras Clave: Juventud. Procesos Formativos. Trabajo.

\section{Notas introdutórias}

Os jovens no Brasil, assim como em outros países, constituíam o grupo social mais escolarizado e mais desempregado e, em certos casos, inscritos em trabalhos precários. Observando os dados nacionais de emprego e desemprego por nível de escolaridade, quer sejam da Pesquisa Nacional por Amostra de Domicílio (PNAD), quer sejam da Pesquisa de Emprego e Desemprego (PED), percebe-se que esse panorama pouco se altera ao longo dos anos.

Embora tenha ocorrido uma significativa elevação do ritmo de crescimento do país e uma geração de novos empregos para toda a População Economicamente Ativa (PEA), especialmente nos anos de 2004 a 2008, como destacou Baltar et al. (2010), os jovens continuam sendo, no Brasil, o grupo mais escolarizado e mais desempregado entre os demais grupos etários. Os dados supracitados tornam complexa a perspectiva instrumental da educação, como se ela fosse capaz, unicamente, de garantir a inserção dos jovens no mercado de trabalho. Entretanto, percebe-se predominantemente um forte investimento à escolarização e à qualificação profissional como uma estratégia capaz de solucionar o fenômeno do desemprego e, sobretudo, o desemprego juvenil.

Partindo desse contexto, pretende-se com este artigo responder : quais são os investimentos pessoais e financeiros, bem como os arranjos construídos pelos jovens, desde 
a educação básica ao ensino superior, na perspectiva da garantia do acesso a "um bom emprego" e uma mudança de posição na estrutura social vigente? Várias contradições serão analisadas para questionar o consenso que a relação entre trabalho e educação parece ser portadora.

Para responder o problema da pesquisa, a opção metodológica construída pautou-se no que Norbert Elias (2000, p. 16) define como estudos microssociológicos, entendendo que estes podem desvelar aspectos encontrados numa escala maior, na sociedade como um todo: "os problemas em pequena escala do desenvolvimento de uma comunidade e os problemas em larga escala de um país são inseparáveis. Não faz muito sentido estudar fenômenos comunitários como se eles ocorressem num vazio sociológico".

O caminho metodológico percorrido aqui aglutinou método, técnicas e instrumentos de pesquisa numa abordagem que articula dados quantitativos e qualitativos, com os quais procuram trabalhar o conteúdo de manifestações da vida social, próprias aos sujeitos que interagem em função de significados (individuais, sociais, culturais, entre outras) e de contextos econômicos e sociais.

Contudo, o material analisado, neste trabalho, é resultante de dois processos distintos e complementares, tendo como objeto de análise inicial as trajetórias dos jovens participantes do Consórcio Social da Juventude de Salvador e RMS ${ }^{1}$. O primeiro momento, realizado entre os anos de 2005 a 2006, tinha como propósito analisar os Percursos de formação construídos pelos jovens ao longo do Consórcio, neste caso, por meio de dez 10 singulares trajetórias. O segundo momento, desenvolvido entre os anos de 2008 a 2011, privilegia a análise da continuidade dos percursos de formação e de trabalho, dos mesmos jovens pesquisados anteriormente $^{2}$, na busca pela inscrição no emprego protegido - denominado por eles de "digno". Para tanto, foram utilizadas as seguintes estratégias: entrevistas exploratórias; entrevistas biográficas, grupos focais e cadernos de campo - com as observações etnográficas - elaborados com o objetivo de registrar o não dito, o não gravado nos momentos das entrevistas.

As trajetórias analisadas se constituem por um conjunto de jovens pobres que mantém e/ou contribuem com as despesas familiares, com idades entre 23 e 26 anos. São residentes de bairros periféricos da cidade de Salvador, na sua maioria considerada favelas de difícil acesso.

\footnotetext{
${ }^{1}$ Projeto construído no governo no início do governo Lula (2003) - parceria entre Ministério do Trabalho e Emprego e a sociedade civil para execução de atividades, com vistas a qualificar jovens para inserção no mercado de Trabalho. Para um maior aprofundamento, consultar Silva $(2009,2012)$

${ }^{2} \mathrm{Na}$ segunda etapa da pesquisa um dos jovens não participou da pesquisa, haja vista que havia sido assassinado pelo tráfico.
} 
São quase todos solteiros e residem dentro de uma configuração familiar, de pais (homem e mulher), irmãos e/ou avós. No conjunto das nove trajetórias analisadas, oito jovens se auto declaram negros e apenas um se declarou mestiço. $\mathrm{O}$ universo analisado predomina o gênero feminino; seis mulheres e três homens. A predominância de mulheres no contingente se deu porque foram, desde o primeiro momento da pesquisa, aquelas que se predispuseram a narrar suas trajetórias de vida, de formação e de trabalho.

Para estabelecer o diálogo das trajetórias com dados estatísticos mais gerais do Brasil e de Salvador foram adicionados a esta análise os levantamentos estatísticos de emprego e desemprego juvenil, disponibilizados pelo(s): Sistema Estadual de Análise de Dados (SEADE)/Departamento Intersindical de Estatística e Estudos Socioeconômicos (DIEESE); Instituto Brasileiro de Geografia e Estatística (IBGE)/Pesquisa Nacional por Amostra de Domicílio (PNAD); Ministério da Educação e Cultura (MEC); e Organização Internacional do Trabalho (OIT).

Assim, por meio do conjunto de técnicas e instrumentos de coletados foi possível construir e analisar nove singulares trajetórias, em uma sequência dos fatos, quase sempre não lineares, ora do presente, ora revisitando o passado, desenvolvendo uma lógica narrativa que procurasse dotar de sentido o que se contava. Cada trajetória analisada foi considerada uma singularidade, um caso de vida de modo que, o objetivo com este conjunto de percursos laborais não foi o de representar o Brasil por meio delas, mas representar uma sociedade na qual muitos casos semelhantes acabam por se refletir.

As categorias teóricas construídas estão presentes em todo o trabalho dialogando, ora com os dados quantitativos, ora com as narrativas das trajetórias de trabalho. Por isso, a trajetória da exposição que se segue está organizada em 3 seções e considerações finais apresentadas a partir de uma lógica construída que melhor orientou a construção deste artigo.

\section{O investimento da Juventude Trabalhadora na educação}

Eu ainda não tenho dinheiro pra pagar uma faculdade, por enquanto vou fazer um curso de inglês, é o que posso. Mas eu vou trabalhar muito, muito mesmo, e vou conseguir realizar o meu sonho - que é fazer Ciências Sociais - e no futuro vou ter um bom emprego. (ANA PAULA, 2010).

A fala de Ana Paula evidencia um sonho de muitos jovens brasileiros que encontram na educação a possibilidade de mudar de posição na estrutura social vigente. Muitos são os jovens - Ana Paula não foge à regra - que crescem cercados de narrativas imbuídas, 
conscientemente ou não, de que a formação seria o passaporte direto para o mundo dos empregos. Assim sendo, vários são os esforços pautados na busca pela garantia do acesso à formação, quer seja por parte dos pais e/ou familiares, quer seja pelos jovens que se apropriam, paulatinamente, da responsabilidade por essa busca.

A passagem do sistema de formação para o sistema de emprego, contudo, não é uma passagem direta. Se algum dia este processo ocorreu, não foi - nem continua sendo - para todos, tampouco para a juventude trabalhadora brasileira ${ }^{3}$. $\mathrm{O}$ acesso direto a um emprego, sinônimo de estabilidade e de inscrição no núcleo da relação fordista, que, durante os anos de 1940 a 1980, caracterizou a transição para o emprego de uma parte dos jovens brasileiros, como destacou Pochmman (2007), é, no contexto atual, privilégio de uma reduzida minoria.

Os dados da tabela, a seguir, informam que a passagem do sistema de formação para o sistema de emprego tem se tornado cada vez mais complexo nos últimos anos. Nos últimos anos houve um aumento da escolaridade na PEA, mais especificamente entre os jovens. No entanto, os números demonstram que, embora o emprego tenha crescido de forma geral para todas as faixas etárias, sobretudo para os ocupados da produção de bens e serviços, reparação e manutenção, os quais detêm nível de escolaridade até o Ensino Médio completo, a taxa de desemprego entre jovens com nível superior incompleto e completo se manteve praticamente inalterada, entre os anos de 2001 e 2009. A partir do crescimento anual do número de jovens desempregados, constata-se que o número de jovens desempregados é maior entre os mais escolarizados (superior completo e incompleto) do que entre os menos escolarizados.

Tabela 1 - Taxa de desemprego dos jovens entre 15 e 29 anos segundo nível de escolaridade Brasil ${ }^{1}$, 2001-2009

\begin{tabular}{lccccc}
\hline \multicolumn{1}{c}{ Escolaridade } & $\mathbf{2 0 0 1}$ & $\mathbf{2 0 0 3}$ & $\mathbf{2 0 0 6}$ & $\mathbf{2 0 0 9}$ & $\begin{array}{c}\text { Taxa anual de } \\
\text { crescimento } \\
\text { (2001/2009) }\end{array}$ \\
\hline Sem Instrução & 9,7 & 9,7 & 10,9 & 13,5 & $-5,6$ \\
Fundamental Incompleto & 14,4 & 13,9 & 12,9 & 14,1 & $-6,5$ \\
Fundamental Completo & 17,5 & 19,1 & 17,0 & 17,3 & $-0,3$ \\
Médio Incompleto & 21,2 & 23,7 & 21,4 & 20,1 & 1,7 \\
Médio Completo & 15,0 & 16,2 & 14,7 & 14,5 & 6,2 \\
Superior Incompleto & 12,8 & 12,8 & 12,9 & 12,5 & 8,4 \\
Superior Completo & 7,5 & 7,4 & 7,7 & 7,5 & 11,4 \\
\hline
\end{tabular}

Fonte: IBGE - PNAD. Elaboração própria.

(1) Exclusive áreas rurais da região Norte.

\footnotetext{
${ }^{3}$ Para um maior aprofundamento, consultar Silva (2012)
} 
Os dados referentes à Região Metropolitana Salvador (RMS) corroboram com a tendência nacional, de relativa manutenção das taxas de desemprego dos jovens e do maior crescimento do número de desempregados entre os jovens mais escolarizados. Em relação ao aumento do desemprego entre os jovens mais escolarizados, observa-se um crescimento, entre 2001 e 2009, de 72\% da População Economicamente Ativa (PEA) jovem com nível superior incompleto e de $150 \%$ da PEA jovem com superior completo. Contudo, verifica-se que o número de desempregados jovens com nível superior incompleto cresceu quase $93 \%$ crescimento maior que o da PEA - enquanto que os desempregados jovens com nível superior aumentaram mais de $140 \%$ - um pouco menos que a PEA. Em valores absolutos, o número de desempregados com nível superior incompleto na RMS passou de 6.480, em 2001, para 12.487 em 2009. Entre os jovens desempregados com nível superior completo, os índices registrados são ainda mais elevados - passando de 2.593 jovens desempregados, em 2001, para 6.246 em 2009.

Assim, os dados evidenciam que o problema do desemprego não se justifica somente pela formação insuficiente dos trabalhadores. Contudo, ainda é disseminada, a promessa de que o investimento na escolarização e na qualificação profissional é a única estratégia capaz de solucionar o fenômeno do desemprego, sobretudo o desemprego juvenil. Para Frigotto (2009), a disseminação desse discurso são promessas que obscurece a realidade, a exemplo do desemprego estrutural e a precarização crescente das condições de trabalho.

Nessa direção, elucida Segnini (2000) que os jovens no Brasil, assim como em outros países do mundo, constituem o segmento mais escolarizado e mais desempregado. A qualificação por si só deixa de ser a garantia para entrada e permanência no "mundo dos empregos”. Assim, é ilusório achar que a qualificação signifique, por si só, emprego. É importante lembrar que um problema grave apresentado à nossa sociedade é também a não empregabilidade dos qualificados.

Inserir os processos educativos e a qualificação profissional numa relação linear com o desenvolvimento econômico e social e com a inserção no mercado de trabalho e, mais recentemente, com as políticas de "formação de competências para a empregabilidade" demonstra as formas mediante as quais o pensamento dominante representa o caminho do enfrentamento das crises constantes e cada vez mais profundas do sistema capitalista. Neste particular, "mais grave do que uma suposta estratégia maquiavélica dos detentores do capital e, na perspectiva de Marx, um condicionamento de classe. Isso nos indica que as saídas para 
a crise não são para uma efetiva superação. Ao contrário, cada crise traz novos elementos que a tornam mais violenta e destrutiva." (FRIGOTTO, 2009, p. 67).

Uma estratégia adotada para a crise do capitalismo, nos países de capitalismo periférico e dependentes, na decáda de 1970 e início dos anos 1980, e que retorna com força ao momento presente é a noção de "capital humano". Nela, o conhecimento é tido como definidor quanto às possibilidades de crescimento econômico, tanto da pobreza quanto dos grandes diferenciais de renda entre diferentes classes sociais. Assim, a tarefa de formação dos recursos humanos passa a ser prioritária; uma vez aumentando a educação dos jovens, estes terão suas habilidades e conhecimentos melhorados e, por conseguinte, terão maior produtividade no trabalho. A maior produtividade, por sua vez, geraria maior competitividade e, assim, maior renda para o indivíduo.

Passaram-se cinco décadas e os resultados da incorporação da "teoria do capital" demonstraram que não surtiu o efeito esperado, ao contrário, concentraram-se mais riqueza e capital, e ampliou-se a pobreza. Entretanto, o mais complexo é como, mesmo depois de um tempo e com seus resultados, seu ideário ainda se inscreve na crença da possibilidade do pleno emprego e, portanto, na perspectiva de integração social dentro de uma sociedade capitalista. Assim sendo, indaga Frigotto (2009, p. 69): como os países pobres e as populações pobres podem adquirir este capital humano? Ou, os países pobres e os jovens pobres assim o são porque têm pouca escolaridade ou têm pouca escolaridade porque são pobres? Para o autor, "quando miramos a realidade, é inequívoca. Sem capital não se gera capital e, portanto, para investir em educação, tanto os países quanto os indivíduos necessitam de capital. O que se elide, uma vez mais, são as relações de poder assimétricas porque são relações, na origem, de classe".

Desse modo, o que os dados aqui informam? Fazendo uso das palavras do sociólogo português Machado Pais (2005), ao analisar a realidade social dos jovens, demonstram que, assim como em Portugal, no Brasil as "profecias também se abatem". Assim como Pais (2005), acredita-se que a formação profissional é indispensável ao bom desempenho de uma atividade profissional. E por isso, mas não somente, é necessário investir mais e melhor na formação profissional dos jovens. Para ele, as dúvidas surgem quando os ideólogos da formação profissional querem nos fazer crer que, ao "decretar-se" a profecia - "falta formação aos jovens" - soluciona-se o problema do desemprego juvenil por meio do investimento à educação. Em consequência, de profecia em profecia, chega-se à conclusão de 
que só com a formação profissional poderão ser ultrapassadas as dificuldades de inserção profissional dos jovens.

Não se pretende negar o valor da escolarização, tampouco da qualificação profissional. Apenas elucida-se a existência de eventuais efeitos perversos associados às profecias que as mesmas tendem a ocultar, especialmente a que estabelece uma relação direta, sem mediações, entre a educação e o desemprego. Assim, é neste movimento que a qualificação se transformou em uma possibilidade de romper a exclusão social, como evidenciou Segnini (2000). Para a pesquisadora, é preciso questionar o consenso do qual a relação entre trabalho e educação parece ser portadora. O desemprego crescente de jovens escolarizados, principalmente nos setores modernos da sociedade, "é tomado como um dos argumentos para tornar relativa essa perspectiva instrumental da educação que se expressa como se fosse capaz de garantir o emprego, ou até mesmo, o trabalho." (SEGNINI, 2000, p. 75).

Assim, fica explícito que, nesse processo de formação de jovens para o mercado de trabalho, não há uma relação direta, única, de causa e efeito, na relação falta de qualificação e desemprego, o que "faz cair por terra" a ideia de que o problema do desemprego juvenil no Brasil, sobretudo na sociedade contemporânea, é exclusivamente decorrente da baixa qualificação dos jovens. Esse é um discurso que se prolifera em diversos espaços, sobretudo no meio empresarial, para justificar a lógica da empregabilidade. Entretanto, os esforços para agregar maior qualificação à força de trabalho não fazem surgir mais empregos. Portanto, buscar as causas do desemprego numa suposta falta de qualificação dos trabalhadores é limitar a análise. Para Pochmann (2006, p. 07), quem determina a empregabilidade é o desempenho da economia, que deve praticar uma política em que são criadas vagas que valorizem a qualificação dos trabalhadores. "É o contrário que vem acontecendo aqui. Ao passo que a população se esforça para elevar a sua qualificação, a economia apresenta um desempenho medíocre com resultados insatisfatórios. Vêm aumentando os índices de quem tem escolaridade e está desempregado.”.

Por meio do discurso dominante, é transmitida a noção de que é necessário um novo perfil para o jovem trabalhador. Embora em alguns casos essas exigências pareçam fundamentais para atender às novas demandas do mercado, muitas vezes exige-se do trabalhador uma qualificação muito acima da necessária para desempenhar a função pretendida e que, na maioria das vezes, pouca relação tem com o posto de trabalho pretendido, como será evidenciado, a partir das trajetórias de trabalho dos jovens pesquisados. 
Contudo, apesar de os dados quantitativos e das análises téoricas apresentadas evidenciarem que o problema do desemprego não tem na falta de formação sua única explicação, circula no imaginário dos jovens pesquisados, assim como no de seus pais, que a educação, por si só, seja capaz de inserir e manter o jovem no emprego e, por conseguinte, garantir as condições materiais necessárias para a mudança de sua posição na sociedade.

Assim, nossa hipotése é de que estamos diante de um receituário resistente ao tempo e às crises do capital, o qual norteia as aspirações e projetos futuros, sobretudo apostando que somente a educação/formação seja capaz de inserir o jovem no bom emprego"4, trabalho estável e, possibilitando, dessa forma, uma mobilidade social ascendente. Nesse movimento, muitos são os investimentos, estratégias e arranjos construídos, quer seja dos jovens, quer seja dos seus familiares.

\section{O Investimento no Ensino Superior}

Embora os jovens já tivessem percorrido vários postos de trabalho, ao longo dos anos da investigação, todos estavam, em 2010, empregados. Contudo, o "emprego decente” e o "trabalho estável", desejados por todos os jovens pesquisados, é algo por vir a ser. Turbulências, flexibilidades e impermanências demarcam as trajetórias de trabalho dos jovens pesquisados; o percurso de Ana é bastante elucidativo neste sentido.

Eu fui pra o Salvador Card trabalhar como Jovem Aprendiz. Fiquei 12 meses e $\log$ o que terminou o contrato eles me mandaram embora. Eu tinha esperança deles me chamarem pra ficar de vez, né? Como uma funcionária de verdade, entendeu? Só que eles não chamaram e aí fiquei numa angústia só, não quero nem lembrar. Aí eu fui novamente pra ruas distribuir currículo. Aí fiz uns bicos ali ou lá e continuei a vida. [...] Aí fui ser garçonete no Pelourinho, mas era pesado demais, minha mão não aguentava, aí fíquei uma semana [...]. Depois eu fui pra outro restaurante melhor, só que eu trabalhava de 10 da manhã até 02 horas da madrugada [...]. Eu ia chegar em casa só umas 4 horas da madrugada, pode isso. Cheguei até ficar doente [...]. Depois de 3 meses eu fui pra outro, como garçonete também, mas esse foi o melhor de todos, viu? Eu trabalhava menos, pegava 11 horas e saía 1 hora e meia da madrugada, e dava o dinheiro do transporte [...]. Graças a Deus eu agora estou na Contax, lá é fogo, tenho cota pra tudo, se eu não bater meu salário vai ficando uma miséria [...]. Eu sei que eu vou conseguir o meu sonho. Não tenho dinheiro pra pagar uma faculdade agora. Como eu não tenho dinheiro tô fazendo um curso de inglês e vou conseguir pagar os estudos [...]. Eu sei que vou fazer Ciências Sociais e vou conseguir um bom emprego. (ANA PAULA, 2009, grifo nosso).

4 Expressão usada quase sempre pelos jovens dessa pesquisa. 
O percurso laboral da jovem Ana Paula, além de apresentar os inúmeros e precários trabalhos percorridos por ela, chama a atenção para um novo redirecionamento no investimento na formação. Se por algum motivo e/ou razão a escola e, por conseguinte, o curso de qualificação profissional feito no Consórcio Social da Juventude, não foram suficientes para garantir o emprego estável e suas respectivas mudanças de posições sociais na estrutura vigente, os trânsitos laborais dos jovens, imersos na cultura da empregabilidade e das competências, foram impondo outra demanda de educação/formação - o Ensino Superior. Assim, mais uma vez, a educação foi convocada não só para resolver o problema do desemprego juvenil, frente ao exército de desempregados, mas, sobretudo, para conseguir um trabalho estável que lhe possibilite condições melhores de vida.

Está claro que quando se demandava desse grupo de jovens uma maior escolarização e mais qualificação, não se referia exclusivamente ao aumento de requisitos cognitivos ou de "competências" específicas para o desempenho de funções rotineiras, pelo menos não neste segmento pouco estruturado do mercado de trabalho em que os jovens são inseridos. Mas, sim, ao fato de que o excesso de oferta de força de trabalho escolarizada e qualificada, já existente e disponível no mercado, opera como um filtro adicional no processo seletivo das empresas.

Contudo, se nos parece claro que as exigências criadas compõem um leque de estratégias para selecionar e filtrar as pessoas, como um jogo de bacará, o qual nos fez lembrar M. Friedman e R. Friedman (1987), para os jovens pesquisados, em nenhum momento, ficou claro esse entendimento, pelo contrário, os jovens se apropriaram deste discurso como sendo o necessário e o urgente nas suas trajetórias. Conquistar o Ensino Superior se configurou para eles como uma questão central, o único passaporte para o (melhor) emprego e, por isso, passou a ser seu próximo investimento. Um investimento que demandou esforços pessoais e familiares que, muitas vezes, ultrapassaram a condição humana.

Para o jovem Alisson, depois de muitas tentativas de aprovação na universidade pública, só lhe restou cursar uma universidade privada. O curso escolhido por ele, fisioterapia, demanda todo o seu salário para pagar a mensalidade. Mas, a vida foi ensinando aos jovens a usar os seus etnométodos; no caso particular de Alisson, usar de suas habilidades esportivas para conseguir um desconto na mensalidade do curso que custa aproximadamente setecentos reais. 
Provavelmente nesse primeiro semestre eu vou ter que ficar tirando esse dinheiro, Seiscentos e setenta e cinco reais, não tem pra onde correr [...]. Mas o que acontece, eu acredito que a partir do segundo semestre eu vou ter conhecimento de como a faculdade trabalha, de como a faculdade funciona. Como eu sou atleta, faixa preta em Tai Kondor, e quando eu falo que eu sou atleta não é brincadeira, realmente é verdade, eu represento o Estado em competições. Eu acredito que vou conseguir descontos através disso [...]. Mas eu garanto que eu vou fazer o que eu puder pra não gastar meu dinheiro todo. Por que senão como vou comer? Eu vou procurar a pessoa da área de marketing, vou procurar o coordenador do curso, seja lá quem for. (ALISSON, 2010).

As trajetórias analisadas evidenciam que todos os jovens estão cursando o Ensino Superior ou estão buscando uma vaga na universidade. Dos nove jovens acompanhados, sete estão no ensino superior e dois estão buscando aprovação em uma das instituições de ensino. Porém, é interessante destacar que todos os que acessaram este nível de ensino foram via ensino privado e, quase todos, cursam ou cursaram as licenciaturas, com exceção do jovem Alisson e da jovem Naira, que faz o curso para tecnólogo em Engenharia de Produção.

Conforme destacou Alves (2008), a expansão do Ensino Superior, nas últimas décadas, em todos os países ocidentais, tem inevitavelmente consequências sobre as características sociográficas da população estudantil. O aumento do número de estudantes traz consigo um alargamento da base social de recrutamento e uma diminuição das desigualdades. No entanto, o acesso a este grau de ensino continua a ser marcado, em muitos países, por uma elevada seletividade social. No Brasil, não é novidade para ninguém que o ensino superior gratuito tem, nos últimos anos, se destinado, principalmente nos cursos de maior valor social, aos jovens que tiveram, ao longo de suas vidas, o privilégio de estudar em "boas escolas" e, possivelmente, puderam usufruir, uma boa parte deles, da juventude como sendo uma etapa de preparação para a vida adulta - moratória social. Também, é possível inferir que, de um modo geral, a atual juventude trabalhadora brasileira, quando acessa a universidade, o faz via ensino superior privado, nos cursos de menor prestígio, geralmente no turno oposto ao seu trabalho, ou à noite, após longas jornadas laborais.

Filha de dona de casa e pai pedreiro, Leidze foi a primeira da família a cursar uma faculdade. "Mostrei para os meus pais que mesmo estudando em escola pública consegui concluir o Ensino Médio, passei no vestibular e em poucos meses vou terminar a faculdade”, conta orgulhosa e diz que, apesar dos pais não conversarem com ela sobre os planos para o seu futuro, sempre a incentivaram a estudar. Ao concluir o Ensino Médio, sua itinerância à procura de uma vaga na universidade pública foi bastante exaustiva. Foi para Itapetinga, no interior do estado, morar com uma tia para tentar o vestibular em Engenharia de Alimentação 
na Universidade Estadual do Sudoeste da Bahia (UESB); também prestou algumas vezes vestibular para Letras na Universidade do Estado da Bahia (UNEB) e Psicologia na Universidade Federal da Bahia (UFBA), mas não conseguiu ser aprovada.

Diferentemente de Leidze, que se submeteu a vários vestibulares em universidades públicas do Estado da Bahia, alguns deles nem mesmo tentaram, ora porque perceberam que suas vidas egressas de escolas públicas deixaram algumas lacunas e "deficiências" 5 - como é o caso de Ana Paula, ora porque a organização em tempo integral de muitos cursos oferecidos pelas universidades públicas os impediam de trabalhar.

A trajetória de Leidze reflete as considerações de Frigotto (2001) quando analisa as articulações entre a educação e a estrutura de classe. De acordo com o autor, os filhos da classe trabalhadora frequentam a escola pública, que não forma cidadãos com perspectivas semelhantes às oferecidas aos filhos da classe dominante. Para o autor, essa desqualificação do ensino expressa a intenção da manutenção das desigualdades nas relações de produção, cujo resultado será a perpetuação da desigualdade em todos os âmbitos.

Para Ana Paula, o sonho da universidade vai esperar um pouco para ser realizado. Suas condições materiais não permitem pagar uma faculdade. Arrimo de família, a jovem, com seu salário mínimo, paga as contas da casa e se mantém com “o pouco que sobra". Seu maior sonho é cursar Ciências Sociais, porém, como bem descreveu a seguir, suas limitações financeiras e de "conhecimento" a impedem de realizá-lo. Ao falar de suas perspectivas futuras, conta-nos:

O que eu queria mesmo era cursar Ciências Sociais, mas é um pouco caro e eu não tenho como pagar, [...]Com meu dinheiro não tem como pagar, porque meu salário é mínimo e quando desconta tudo que tem que descontar não sobra quase nada. Além de me alimentar e de manter minha casa, telefone, água. Ainda tenho que cuidar de mim e comprar roupa, sapato, ir numa festa, que esse tipo de coisa assim, né? [...]. Então, não dá pra eu cursar o curso que eu quero que é Ciências sociais, então eu me contento em fazer um curso de inglês nos próximos meses e ver se melhora a situação. Eu só posso fazer Católica, a UFBA não é pra mim. A federal é pra quem tem um bom conhecimento e eu não tenho, porque eu não tenho como pagar um curso pré-vestibular, e exige muito conhecimento mesmo, não é para amador não, é pra quem realmente é fera, eu não sou essa fera toda não. Eu tentei fazer um pré-vestibular da UFBA, paguei pela prova e não passei no prévestibular. Se eu não passei no pré-vestibular imagina no vestibular da UFBA que é mais complicado passar. (Ana Paula, 2010).

5 Como destacou Ana Paula. 
O relato da jovem evoca um diálogo muito estreito com as pesquisas pioneiras de Bourdieu e Passeron, na década de 1960, sobre a composição social dos estudantes franceses. As pesquisas dos dois sociólogos se inscrevem numa época em que a igualdade de oportunidades se transformara num princípio orientador da política educativa francesa. As probabilidades de ascender ao Ensino Superior estavam, como demonstram, fortemente relacionadas à origem social. Afirmam os autores (BOURDIEU; PASSERON, 1964, p. 12) que "um filho de um quadro superior tem oitenta vezes mais de probabilidades de ascender à Universidade do que um filho de um assalariado agrícola, quarenta vezes mais do que um filho de operário e as suas probabilidades são ainda duas vezes superiores à de um filho de um quadro médio". Nesse estudo, pontuam que a desigualdade não se relaciona apenas ao acesso à universidade, mas se manifesta também no seu interior, através da oposição entre os cursos em que mais receptivos aos filhos das classes populares e aqueles que lhes continuam praticamente vedados. O Ensino Superior é, assim, marcado por uma sobre seletividade social, entre os cursos em se verifica uma abertura social e aqueles outros em que impera um forte fechamento social. (BOURDIEU; PASSERON, 1964, p. 19).

Pioneiros por analisar a seletividade interna da universidade e do dualismo social que operava a sociedade francesa, Bourdieu e Passeron (1964, p. 19) defendem que as dificuldades econômicas não eram suficientes para explicar as variações tão acentuadas das taxas de "mortalidade escolar" em função da origem social. Assim, argumentam, "a eficácia dos fatores de desigualdade é tal que, mesmo que se verificasse uma equalização dos meios econômicos, o sistema universitário continuaria a consagrar as desigualdades" (BOURDIEU; PASSERON, 1964, p. 44). Para os sociólogos, a diferença é explicada pelo capital cultural e pelo sistema de disposições herdado do meio familiar - ethos. São eles que, na opinião de Bourdieu (1998), explicam as condutas escolares e as atitudes face à escola, e são precisamente estas últimas que constituem o princípio de eliminação diferencial dos estudantes das diversas classes sociais.

Se por um lado, entretanto, é inquestionável que as probabilidades objetivas de acesso à universidade variam em função da classe social, por outro, Bourdieu e Passeron (1964) chamam também a atenção para o fato de estas variações objetivas serem alvo de uma apropriação subjetiva. Estas últimas explicam o fato da carreira universitária ser concebida como parte de um futuro impossível para alguns e possível ou normal para outros. Partilhando uma imagem dos estudos superiores como algo que lhes é inacessível, os jovens pobres alimentam esperanças subjetivas inferiores às suas probabilidades objetivas. Assim, 
neste movimento entre esperanças subjetivas, ou "desesperanças subjetivas" (BOURDIEU, 1998, p. 49) e oportunidades objetivas, é que reside parte da explicação para a desigualdade verificada no acesso à universidade6. Isto, na perspectiva de Bourdieu, explicaria o discurso de Ana Paula, ao se referir à sua incapacidade de acessar a Universidade Federal da Bahia. As trajetórias dos jovens pesquisados, todavia, em especial de Ana Paula, longe de representarem esperanças inferiores às suas probabilidades objetivas, significam limitações reais de jovens pobres que, diante dos seus percursos de exclusão, conseguem perceber as reais barreiras que os separam do ensino público.

Contudo, o conjunto das trajetórias analisadas indica que a tomada de consciência das barreiras sociais está sempre relacionada aos percursos de exclusão vividos pelos jovens; quanto mais fortes e presentes foram/são as necessidades e, por conseguinte, as limitações frente às suas perspectivas futuras, mais clareza têm os jovens sobre suas reais possibilidades, como se pode perceber a partir da trajetória de Juthan.

Nos primeiros contatos com o jovem Juthan, em 2005, ele já informara que cursar história estava em seus planos; ainda não havia ficado evidente, contudo, sua compreensão das barreiras sociais impostas para a materialização do seu sonho. Em 2010, ao falar de sua vida estudantil, trouxe alguns elementos novos de análise:

No segundo e terceiro ano eu já estava praticamente certo, queria fazer História mesmo, só não sabia como, porque a única faculdade que oferecia o curso de História era a UFBA, UNEB e a Católica. Antes eu até pensava em fazer uma pública, mas com o tempo eu fui me dando conta das minhas possibilidades. Eu costumava dizer que o curso da UNEB eu não ia fazer, porque eu não poderia estar trabalhando, porque os horários não eram compatíveis; se eu ficasse o dia todo na faculdade quem ia me manter, eu e a minha família? Eu tinha que trabalhar, se eu não trabalhasse eu ia comer capim (risos)? Porque nem transporte de voltar eu ia ter. Então pensei: - vou fazer uma escola particular; a única particular que tinha era a Católica. Mas também pensei: - eu vou ter que ter um emprego bem bacana, que a Católica é oitocentos reais a mensalidade. (JUTHAN, 2010).

O depoimento de Juthan também pode iluminar outras trajetórias de jovens pobres, que, quando conseguem chegar à universidade, percorrem cursos de menor valor social e combinam trajetórias de subemprego, contratos temporários, (des)emprego, com a vida estudantil. Muitas vezes, o trabalho, nas múltiplas configurações do tempo presente, é a única

6 Segundo Bourdieu (1966, p. 331-332), são as esperanças subjetivas que levam os filhos dos operários a renunciarem à escola e os da pequena burguesia a ela aderirem e a nela verem o veículo, por excelência, de ascensão social. 
forma de manter esse jovem no curso. Foi o que aconteceu com o contingente de jovens pesquisados, todos eles conciliaram longas jornadas de trabalho diárias com estudo.

Trabalhar e estudar ao mesmo tempo foi muito complicado pra mim, foi aterrorizante. Porque assim, eu tinha que trabalhar, eu trabalhava no hotel das oito da manhã às quinze horas da tarde e aí quando eu saía da do trabalho eu ia pra faculdade. [...] eu estava desenvolvendo vários papéis que eu não tinha consciência disso. No hotel, eu era funcionária, na faculdade, uma estudante, em casa eu era filha, irmã e eu não tinha consciência disso porque, às vezes, tudo se misturava. E aí tinha hora em que eu era filha no lugar de estudante, tinha hora que era estudante no lugar de funcionária e aí aquilo foi dano um nó na minha cabeça, mas eu consegui superar. Eu tinha que colocar a cara no livro pra estudar nas poucas horas da madrugada que eu tinha, eu tinha que contactar amigos de faculdade, saber o que foi que o professor tinha dado se caso eu tivesse faltado à aula, e era muito desgastante. Porque, às vezes, eu chorava muito à noite querendo saber se eu iria concluir a minha faculdade. (IRANILDES PAULA, 2010).

Além dos dilemas vividos pela dimensão de ser jovem estudante e trabalhador, os jovens que ingressaram no Ensino Superior, mesmo aqueles com bolsas que custeiam parte ou integralmente o valor de suas mensalidades, vivem o fantasma constante de a qualquer momento, pela sua instabilidade no emprego, não poder pagar seus estudos e/ou todas as demandas que circunscrevem a vida universitária. A narrativa da jovem Leidze exemplifica esse dilema:

Em 2007, eu entrei em Letras. Eu trabalhava a semana inteira e saía correndo para faculdade, além do sábado que também estudava. Mesmo quando eu estava trabalhando o meu maior medo era ficar desempregada, mas eu até evitava pensar muito [...]. Quando terminou meu contrato, eu disse: meu Deus o que eu vou fazer da minha vida? Como eu vou me manter estudando? Como eu vou sobreviver? [...] Mas eu continuei estudando e buscando, colocando currículo, fazendo entrevista, me cadastrei em algumas empresas de RH. Saía seis da manhã pra entregar currículo e voltava cinco da tarde todos os dias. Assim, tinha dias que eu não tinha nem o dinheiro pra transporte, mas aí eu dizia assim: me empreste aí o transporte, mãe, tia, quem tivesse, pra poder correr atrás, batalhar mesmo. (LEIDZE, 2010).

Assim, uma das grandes questões que se coloca não é apenas o acesso do jovem ao Ensino Superior, mas também como mantê-lo diante de suas questões materiais de existência. Contudo, a questão da entrada do jovem no Ensino Superior ganha maior centralidade, porque, embora se constate uma ampliação significativa de acesso, sobretudo entre jovens, na qual a taxa de frequência mais que dobrou no período de 2001-2009, o patamar alcançado ainda se encontra muito aquém do desejado, tanto em relação à meta estipulada pelo Plano Nacional de Educação (PNE), de 30\%, a ser atingida em 2011, quanto na comparação com os demais países latino-americanos, conforme destacou Corbucci et al. (2009). De acordo com 
estudo do Instituto Internacional para a Educação Superior na América Latina e Caribe (IESALC)7, vinculado à Organização das Nações Unidas para a Educação, a Ciência e a Cultura (Unesco), o Brasil apresentava, em 2003, uma das menores taxas brutas de matrícula na educação superior da América Latina8, assim como uma das menores proporções de estudantes de Ensino Superior por 10 mil habitantes.

As marcas das desigualdades na frequência à educação superior entre jovens de 15 a 29 anos são mais expressivas quando analisadas as variáveis - renda, cor/raça e gênero. Segundo Corbucci et al. (2009), quando se considera a variável renda, verifica-se que a taxa de frequência oscila de 5,6\%, para os que têm rendimentos mensais per capita de meio a um salário mínimo, até $55,6 \%$, para os jovens que se encontram na faixa de cinco salários mínimos ou mais. Por sua vez, as desigualdades observadas a partir da condição de raça/cor mantêm-se bastante acentuadas, em que pesem os avanços ocorridos ao longo dos últimos 15 anos, na medida em que negros apresentam taxa de apenas $35 \%$ da registrada entre brancos. No tocante ao recorte sexo, as mulheres são mais escolarizadas que os homens, reiterando uma tendência mais expressiva nos anos mais recentes. Verifica-se que as mulheres jovens estão mais presentes no Ensino Superior, assim como nos demais níveis de ensino, em relação aos jovens homens.

O Conselho Nacional da Juventude, preocupado com as dificuldades de acesso ao Ensino Superior da juventude brasileira, já em 2006, em suas diretrizes para a Política Nacional de Juventude, apontava a grande debilidade de acesso à universidade para os jovens; naquele período, apenas $12 \%$ da população juvenil frequentava o Ensino Superior, sendo que mais de $70 \%$ dos jovens que concluía o Ensino Médio não ingressam no Ensino Superior e esta situação se mantém pouco alterada nos dias atuais.

Cabe então indagar: em que tipo de curso os jovens pobres ingressam? Qual é a modalidade de Ensino Superior mais frequente de acesso? Como têm se configurado suas trajetórias no Ensino Superior?

A análise das trajetórias pesquisadas pode contribuir para evidenciar um novo fenômeno sociológico ou uma nova dinâmica na configuração do Ensino Superior brasileiro. Se houve, na história recente, um momento histórico no qual mais jovens trabalhadores conseguiam ter acesso (não afirmando aqui que eles tenham permanecido) ao Ensino Superior privado, no momento presente, esse processo tem se estratificado, no interior do próprio

7 Ver IESALC/UNESCO (2006).

8 Correspondente, neste caso, ao total de matrículas na educação superior dividido pela população nessa faixa etária. 
Ensino Superior privado: jovens trabalhadores com baixa renda per capita chegam numa proporção ascendente a uma modalidade específica do Ensino Superior - o ensino a distância.

\section{Cursos à distância: a juventude trabalhadora brasileira chega à terra prometida?}

Pode não ser por acaso que dos seis jovens desta pesquisa que conseguiram acessar o ensino superior privado, cinco deles estão inscritos em cursos a distância. Embora o conjunto de trajetórias aqui analisadas não represente de forma quantitativa de análise, uma amostragem relevante para uma conclusão, levanta-se a hipótese de que a juventude trabalhadora brasileira ao chegar ao Ensino Superior (quando o alcança) tem tido uma rota estudantil crescente e determinada ao ensino a distância, mais precisamente aquela que tem renda per capita de até três salários mínimos, quer seja alcançada por esforços pessoais e familiares, quer seja, sobretudo, via Programa Universidade Para Todos (ProUni). Ver quadro a seguir

Quadro 1 - Jovens pesquisados e nível de escolaridade por modalidade de ensino Salvador, 2010

\begin{tabular}{|l|c|c|c|c|}
\hline \multicolumn{1}{|c|}{ Nome } & Escolaridade & $\begin{array}{c}\text { Público ou } \\
\text { Privado }\end{array}$ & Bolsista & Modalidade \\
\hline Álisson Bonfim & Superior Incompleto & Privado & ProUni & Presencial \\
\hline Juthan Santos da Rocha & Superior Incompleto & Privado & Bolsa Sind & A Distância \\
\hline Luciana Santiago Souza & Superior Incompleto & Privado & ProUni & A Distância \\
\hline Iranildes Paula dos Santos & Superior completo & Privado & ProUni & A Distância \\
\hline Naiara Cerqueira Silva & Superior Incompleto & Privado & ProUni & A Distância \\
\hline Leidze Cristina da Silva & Superior incompleto & Privado & ProUni & A Distância \\
\hline Daniel Rocha Souza & Médio Completo & Publico & X & Presencial \\
\hline Vanessa de Jesus Silva & Médio Completo & Público & $\mathrm{X}$ & Presencial \\
\hline Ana Paula Dom Passos & Médio Completo & Público & $\mathrm{X}$ & Presencial \\
\hline
\end{tabular}

Fonte: pesquisa de campo realizado pelo autor. Elaboração própria.

As trajetórias dos cincos jovens que cursam o Ensino Superior a distância, Juthan, Luciana, Iranildes, Naiara e Leidze, estão inscritas dentro de uma estratégia governamental de ampliação ao Ensino Superior. Devido ao baixo índice de frequência à educação superior e às dificuldades de acesso que limitam o jovem galgar o terceiro grau, seja de renda, cor/raça, gênero e região, o governo federal, via Ministério da Educação, tem adotado um conjunto de 
ações e medidas voltadas a atenuar esse quadro. Para além da ampliação do número de vagas no Ensino Superior público, via expansão da rede de Instituições Federais de Ensino Superior (IFES), uma estratégia adotada tem sido o expressivo crescimento das matrículas na modalidade de ensino a distancia, especialmente via incentivo à expansão do ensino privado9.

Como um dos mecanismos auxiliares de financiamento usado para viabilizar a expansão do acesso ao Ensino Superior, foi instituído, em 1999, o Fundo de Financiamento ao Estudante do Ensino Superior (Fies), em substituição ao Programa de Crédito Educativo. Favorecidas por essa iniciativa, conforme destacou o relatório publicado pelo IPEA (2009, p. 103), as matrículas nas instituições privadas tiveram crescimento de $132 \%$ no período de 1997 a 2003. Por sua vez, "o ritmo de crescimento da oferta de vagas pelo setor privado foi ainda mais intenso, tendo atingido $241 \%$ nesse período. Tal defasagem entre oferta e demanda gerou elevado percentual de vagas ociosas, algo como $50 \%$ do total oficialmente declarado pelas instituições de ensino". Outro mecanismo adotado pelo Governo Federal, e que para Catani (2006) surge como excelente oportunidade de fuga para frente para as instituições ameaçadas pelo peso dessas vagas excessivas, é o Programa Universidade para Todos (ProUni) - programa que contempla com bolsas parciais e integrais cinco jovens desta pesquisa - Juthan, Luciana, Iranildes, Naiara e Leidze.

Convém destacar que, desde a sua proposta inicial, o ProUni causou muitas polêmicas entre as organizações ligadas à educação superior e que atuam na defesa do ensino público. A renúncia fiscal que o caracteriza era combatida por ocasião da sua implantação, dado que viria a somar ao montante de 839,7 milhões que o Estado deixava de arrecadar com as instituições filantrópicas, conforme destacou a análise do Grupo de trabalho de Política Educacional da a Associação Nacional dos Dirigentes das Instituições Federais de Ensino Superior (ANDIFES). E, no mesmo ano (2004), este mesmo grupo, apontava a necessidade de verbas emergenciais de 58 milhões para as IFES10. É importante destacar que o Estado brasileiro adotou a prática de criar taxas e contribuições, nas quais não incidem os recursos destinados à educação. Ou seja, ainda que haja aumentos percentuais, eles incidirão em um montante que não representa a arrecadação estatal total. Entretanto, as análises apontavam que o aspecto mais grave da proposta era:

9 Segundo Corbucci et al. (2009), esta orientação teve início com a substituição do então Conselho Federal de Educação (CFE) pelo CNE, sem o poder deliberativo do seu antecessor.

10 Análise do Grupo de Trabalho de Política Educacional/ANDES, Brasília, agosto de 2004. 
Caso o PROUNI seja aprovado, aproximadamente 1125 instituições gozarão de isenções fiscais. Embora estudos adicionais tenham de ser feitos, é razoável supor que o montante será extremamente elevado. Estudo da Andifes sugere que com $\mathrm{R} \$ 1$ bilhão seria possível dobrar o número de estudantes nas IFES. (ANDES, 2004).

Entretanto, o ProUni surgiu no contexto da reforma universitária do Governo Lula como a promessa de democratizar o acesso da população de baixa renda ao ensino superior. Desde quando o projeto de lei foi encaminhado ao parlamento, em maio de 2004, até a versão definitiva, em janeiro de 2005, o programa sofreu diversos ajustes, influenciados, como bem destacou Catani (2006), pelas instituições de Ensino Superior e beneficentes.

Conforme consta no site do MEC (2012), o ProUni, concede bolsas 11 de estudos em instituições privadas para estudantes que tenham renda familiar per capita de até três salários mínimos. Para concorrer a uma bolsa, o estudante deve participar do Exame Nacional do Ensino Médio (Enem), na edição imediatamente anterior ao processo seletivo do ProUni, e obter a nota mínima nesse exame, estabelecida pelo MEC. Deve, também, ter renda familiar de até três salários mínimos por pessoa e ter cursado o Ensino Médio completo em escola pública ou em escola privada com bolsa integral da instituição; ter cursado o Ensino Médio parcialmente em escola pública e parcialmente em escola privada com bolsa integral da instituição; ser pessoa com deficiência; ser professor da rede pública de ensino básico, em efetivo exercício, integrando o quadro permanente da instituição, e estar concorrendo a vaga em curso de licenciatura, normal superior ou pedagogia12.

Um dos critérios adotados para que o aluno permaneça com a bolsa ao longo do curso é seu aproveitamento acadêmico de, no mínimo, $75 \%$ (setenta e cinco por cento) nas disciplinas cursadas em cada período letivo, sob pena de encerramento da bolsa. Em caso de aproveitamento acadêmico insuficiente, o coordenador do ProUni poderá ouvir o responsável pela(s) disciplina(s) na(s) qual(is) houve reprovação e autorizar, por uma única vez, a continuidade da bolsa.

Este critério de aproveitamento parece aquém de uma reflexão do perfil do contingente beneficiado pelo programa. Na sua grande maioria, são estudantes trabalhadores que conciliam excessivas horas de trabalho com estudo, como é o caso dos jovens desta pesquisa.

11 As bolsas podem ser parciais ou integrais. A bolsa integral é destinada para estudantes que possuam renda familiar, por pessoa, de até um salário-mínimo e meio; A bolsa parcial, de 50\%, é para estudantes que possuam renda familiar, por pessoa, até três salários-mínimos A bolsa parcial de $25 \%$ é para estudantes que possuam renda familiar, por pessoa, até três salários-mínimos.

12 Neste caso, a renda familiar por pessoa não é considerada. 
Observando seus percursos, percebe-se que este critério é motivo de angústia para todos eles.

O depoimento de Iranildes Paula põe luz sobre isso:

Trabalhando eu podia bancar a minha faculdade, podia ajudar financeiramente em casa, que era o que acontecia. Eu pagava meu transporte, pagava meu lanche, meus módulos, meus seminários, tudo relativamente a minha faculdade eu bancava. O governo bancava a minha mensalidade e a cada seis meses ele fazia uma concessão de bolsa, pra saber se eu tinha tido aproveitamento e não tinha falta. Poderia ser cortada a qualquer momento. Isso é muito angustiante, por mais que eu me esforçava, era muito complicado ter o aproveitamento que eles exigem. O pouco tempo que tinha pra estudar eu chegava morta de cansada, quantas vezes eu apaguei com a cara nos livros? (IRANILDES, 2009).

Embora o Governo, em 2006, tenha criado a Bolsa-permanência, destinada a ajudar no custeio das despesas educacionais dos estudantes, Iranildes e os outros jovens desta pesquisa contemplados pelo ProUni - apesar de serem jovens de baixa renda e necessitarem conciliar trabalho e estudo - não estavam dentro do perfil atendido, uma vez que o benefício, de até $\mathrm{R} \$$ 300,00 mensais, era concedido a estudantes com bolsa integral em utilização, matriculados em cursos presenciais13, o que não é a realidade desses jovens - todos eles estão/estiveram no ensino superior a distancia.

Segundo os dados oficiais, o ProUni, desde a sua criação até o processo seletivo do segundo semestre de 2011, já atendeu 919 mil estudantes, sendo 67\% com bolsas integrais, conforme publicou o Ministério da Educação (2012). Contudo, é importante destacar que este número ainda é pouco expressivo frente ao contingente de jovens que estão à margem do Ensino Superior, como já apresentado anteriormente.

Apesar de o "discurso oficial" apontar o programa como uma experiência exitosa de ampliação ao acesso ao Ensino Superior, os resultados quantitativos apresentados, no quadro a seguir, somados às trajetórias em análise, informam que - além da oferta de vagas ser muito menor que a demanda reprimida - não contribui para uma futura igualdade de oportunidades de acesso ao mercado de trabalho, tampouco favorece a redução das desigualdades que circunscrevem o Ensino Superior, apenas as deslocam, assumem novas configurações

TABELA 2 - Evolução da Educação a Distancia no Brasil 2002-2010

13 Com no mínimo seis semestres de duração e com carga horária média superior ou igual a seis horas diárias de aula. De acordo com os dados cadastrados pelas instituições de ensino no Sistema Integrado de Informações da Educação Superior (Siedsup), mantido pelo Instituto Nacional de Estudos e Pesquisas Educacionais Anísio Teixeira (Inep). 


\begin{tabular}{lrrrrrrr}
\hline \multicolumn{1}{c}{ EAD } & $\mathbf{2 0 0 2}$ & $\mathbf{2 0 0 4}$ & $\mathbf{2 0 0 6}$ & $\mathbf{2 0 0 8}$ & $\mathbf{2 0 1 0}$ & $\begin{array}{c}\text { Taxa de } \\
\text { Cresc. Anual } \\
\text { (\% a.a.) }\end{array}$ & $\begin{array}{c}\text { Taxa de } \\
\text { Cresc. no } \\
\text { período }(\%)\end{array}$ \\
\hline Número de Cursos & & & & & & & \\
Vagas Oferecidas & 24.389 & 113.079 & 813.550 & 1.699 .489 & 1.634 .118 & 69,1 & $1.921,7$ \\
Candidatos Inscritos & 29.702 & 50.706 & 430.229 & 708.784 & 690.921 & 48,2 & $6.600,2$ \\
Ingressos & 20.685 & 25.006 & 212.246 & 463.093 & 380.328 & 43,9 & $1.738,7$ \\
Matrículas & 40.714 & 59.611 & 207.206 & 727.961 & 930.179 & 47,9 & $2.184,7$ \\
Concluintes & 1.712 & 6.746 & 25.804 & 70.068 & 144.553 & 74,1 & $8.343,5$ \\
\hline
\end{tabular}

Fonte: INEP - Sinopse da Educação Superior. Elaboração própria.

A ampliação de cursos e vagas oferecidas de 2002 a 2010 no Ensino Superior a distancia, conforme elucida a tabela anterior, de mais de $8.000 \%$ em menos de uma década, indica uma forte tendência adotada pelo governo para ampliação do acesso, impelida e ancorada especialmente pelo ProUni. Contudo, se esta expansão tem como finalidade atender às metas do Plano Nacional de Educação (PNE) e dos patamares internacionais exigidos, e contribuir, sobretudo, para a qualificação dos jovens com vistas a uma melhor oportunidade de acesso ao mercado de trabalho, é mais uma proposta que obscurece a (futura) realidade, uma vez que a estratificação do ensino superior privado - ensino presencial e ensino a distância - intensifica ainda mais acesso desigual ao mercado de trabalho, por parte da juventude trabalhadora brasileira.

Desde a década de 1960, Raymond Ledrut chama a atenção para o fato de que a seletividade é um princípio da composição relativa ou diferencial das populações desempregadas; uma vez havendo desemprego, haverá grupos preteridos, característica que, segundo o autor, pode variar quanto à sua intensidade, segundo a demanda geral por trabalhadores, por características sociais ou particulares, pela diferenciação a partir de condições individuais ou dos grupos que compõem a mão-de-obra (LEDRUT, 1966). Nesse mesmo sentido, Claus Offe, em meados de 1980, diante do alto desemprego nos países avançados, também elucida que em meio a um elevado desemprego, alguns trabalhadores ficam e permanecem mais constantemente desempregados do que outros, além de, em geral, obterem renda inferior à média de seus pares. Isso, para Offe, decorre das condições de maior exposição de determinados grupos ao desemprego e às mazelas promovidas pelo funcionamento do sistema econômico. Tais condições podem derivar de características sociais não adquiridas - educação, renda, local de residência - mas socialmente atribuídas e ligadas a aspectos fixos e intencionalmente imutáveis, tais como idade, sexo, condição física, etnia, entre outros (OFFE, 1989). 
Assim, quanto maior a expansão dos desempregos, maior será a seletividade na inserção dos jovens, com ensino superior completo, no mercado de trabalho. Seletividade que só intensifica quando acionadas as questões da cor/raça e gênero.

Outro ponto que nos chama a atenção, a partir dos dados a seguir, e que tem uma relação direta com a seletividade do mercado e com as trajetórias pesquisadas, é a área de conhecimento de maior ampliação da oferta de cursos superiores a distancia. Conforme os dados apresentados, a área de educação apresenta maior crescimento no período de tempo analisado, de 2002-2010. Tamanho crescimento de 46 cursos da área de educação, em 2002, para 518 cursos, em 2010, pode reconstruir perguntas feitas neste capítulo: qual a modalidade de Ensino Superior mais frequente de acesso? Qual área de conhecimento direciona com maior frequência a juventude trabalhadora brasileira?

TABELA 3 - Evolução da educação a distancia por área de conhecimento do curso superior Brasil 2002-2010

\begin{tabular}{|c|c|c|c|c|c|c|}
\hline Áreas Gerais dos Cursos & $\begin{array}{l}\text { Número de } \\
\text { Cursos }\end{array}$ & $\begin{array}{c}\text { Vagas } \\
\text { Oferecidas }\end{array}$ & $\begin{array}{c}\text { Candidatos } \\
\text { Inscritos }\end{array}$ & Ingressos & Matrículas & Concluintes \\
\hline \multicolumn{7}{|c|}{2002} \\
\hline Total & 46 & 24.389 & 29.702 & 20.685 & 40.714 & 1.712 \\
\hline Educação & 44 & 22.739 & 27.993 & 19.671 & 40.179 & 1.712 \\
\hline Humanidades e Artes & - & - & - & - & - & - \\
\hline \multicolumn{7}{|l|}{ Ciências Sociais, Negócios e } \\
\hline Direito & 1 & 1.500 & 1.445 & 864 & 385 & 0 \\
\hline \multicolumn{7}{|l|}{ Ciências, Matemática e } \\
\hline Computação & 1 & 150 & 264 & 150 & 150 & 0 \\
\hline \multicolumn{7}{|l|}{ Engenharia, Produção e } \\
\hline Construção & - & - & - & - & - & - \\
\hline Agricultura e Veterinária & - & - & - & - & - & - \\
\hline Saúde e Bem-Estar Social & - & - & - & - & - & - \\
\hline Serviços & - & - & - & - & - & - \\
\hline \multicolumn{7}{|c|}{2010} \\
\hline Total & 930 & 1.634 .118 & 690.921 & 332.028 & 930.179 & 144.553 \\
\hline Educação & 518 & 591.008 & 261.106 & 128.235 & 425.355 & 71.823 \\
\hline $\begin{array}{l}\text { Humanidades e Artes } \\
\text { Ciências Sociais. Negócios e }\end{array}$ & 14 & 26.179 & 3.912 & 1.636 & 4.528 & 431 \\
\hline Direito & 295 & 737.265 & 300.473 & 145.715 & 351.403 & 49.824 \\
\hline \multicolumn{7}{|l|}{ Ciências, Matemática e } \\
\hline \multicolumn{7}{|l|}{ Engenharia, Produção e } \\
\hline Construção & 15 & 14.378 & 19.338 & 7.415 & 12.101 & 1.891 \\
\hline Agricultura e Veterinária & 7 & 3.790 & 1.574 & 535 & 1.830 & 177 \\
\hline
\end{tabular}




\begin{tabular}{lrrrrrr} 
Saúde e Bem-Estar Social & 17 & 119.030 & 50.123 & 21.614 & 75.141 & 9.046 \\
Serviços & 25 & 31.328 & 25.321 & 13.330 & 31.710 & 7.628 \\
\hline
\end{tabular}

Fonte: INEP - Sinopse da Educação Superior. Elaboração própria.

Os dados supracitados informam o vetor da estratégia das políticas de ampliação do acesso ao ensino superior no Brasil. A alocação dos estudantes pobres nas instituições particulares, nos cursos a distancia e, principalmente, nos cursos inscritos no campo da educação, cristalizará ainda mais a dinâmica de segmentação e diferenciação do sistema de formação para o sistema de emprego. Destinando, primeiramente, às universidades academicamente superiores para aqueles que conseguem passar nos vestibulares das instituições públicas, geralmente aqueles que tiveram condições de experienciar educação de qualidade, e as faculdades e centros universitários, academicamente mais fracos, salvo exceções, para os pobres que agora conseguem, via ensino superior a distancia, acessá-los. $A$ posteriori, o filtro social e a própria seletividade do mercado, na ausência de empregos suficientes para os graduados, adicionarão no leque de critérios de seleção o lugar da conclusão e a modalidade de ensino como sendo principais pontos definidores das trajetórias de trabalho, bem como de inclusão ou exclusão do jovem no mercado de trabalho, podendo, inclusive, transformar, esses diplomados em "supramunerários"14 de um futuro próximo.

\section{Considerações Finais}

Na pesquisa ora realizada, buscou-se, por meio de nove singulares trajetórias, analisar os percursos laborais por eles construídos. Por meio deles pretendeu-se contribuir para a compreensão que se estabelecem com o trabalho e a educação. Para tanto, objetivou-se analisar os investimentos pessoais e financeiros, bem como os arranjos familiares construídos no campo da formação na procura de melhores condições de acesso e permanência no emprego. Desta forma, buscou-se contribuir para a compreensão das relações sociais vividas por este segmento da heterogênea juventude trabalhadora, no país.

A relação entre trabalho e educação ganha centralidade nas trajetórias pesquisadas. Por meio dos percursos analisados, constatou-se que há um forte discurso em favor da educação como sendo, se não a única, a principal estratégia de mobilidade social ascendente.

14 Jovens que não possuem inscrição em estruturas portadoras de um sentido, a exemplo do emprego (CASTEL, 1998, p. 536) 
Os primeiros investimentos e arranjos realizados, na perspectiva da obtenção deste emprego, foram centrados nos esforços para que esses jovens conseguissem a conclusão do ensino médio e, assim, o fizeram. Quando terminaram o ensino médio - nível de ensino que décadas passadas significou, para alguns, maiores possibilidades de transição da escola para o trabalho - o emprego almejado não foi encontrado. Seus trânsitos laborais se inscreveram em "bicos", "um trabalho ali e outros acolâ" para escapar de condições aviltantes do nãoemprego e, especialmente, garantir condições básicas de sobrevivência.

À medida que o tempo passava, as inúmeras dificuldades enfrentadas na busca pela inscrição no emprego tornavam-se cada vez mais onipresentes, mas não desanimadoras. Apesar da tensão entre presente e futuro, das encruzilhadas de sentidos vários, becos de circulação difícil, ou mesmo sem saídas15, os jovens pesquisados apresentavam um "experiência expectante", definida por Ernst Bloch (2005)16, como modo da possibilidade e da futuridade, como um horizonte sempre aberto de realização do possível, um sinal de mudança, num "novum" capaz de romper a vida cotidiana e anunciar um tempo novo.

Contudo, se por um lado é possível perceber, por meio das narrativas dos jovens, uma esperança mobilizadora em projetos futuros, por outro, também é visível que essa busca se inscreve na compreensão de que a saída do desempregado, da sua condição de pobre, dependia exclusivamente de seus esforços pessoais e familiares em conseguir "competências" para "a empregabilidade". Desse modo, é reiterada uma incorporação, por parte dos jovens, das ideias presentes na teoria do capital humano17 que, décadas depois, se redimensiona no campo da formação, fortemente presente na lógica das competências (FRIGOTTO, 2009).

Nesta contradição aparente, pelo menos ao pesquisador deste trabalho, os jovens percebem que era preciso ir além do ensino médio e, assim, pleitearam e conseguiram participar dos cursos de qualificação profissional oferecidos pelo Consórcio Social da Juventude de Salvador e Região Metropolitana - um dos projetos do Programa Nacional de Estimulo ao Primeiro Emprego. Conclui-se que o resultado dessas trajetórias de qualificação para o trabalho garantiu a esses jovens, em especial, uma primeira experiência laboral, mas

15 Semelhantes aos jovens portugueses pesquisados por Pais (2005) e por Alves (2008).

16 Ernst Bloch, Ernst (2005), na II parte "A consciência antecipadora", do primeiro livro da trilogia "O princípio esperança", define o "sonho diurno" e as idealizações juvenis enquanto "horizonte da realização, do fazer, da realização da possibilidade", na medida em que se abre aos conteúdos da consciência antecipadora, um "sinal de mudança", um "novum" capaz de romper a apatia da vida cotidiana e anunciar um "tempo novo". Bloch ressalta que a "mania de querer o melhor" continua presente no homem como motivo de despertar e de futuro, mesmo quando as circunstâncias históricas o impedem e oprimem (BLOCH, 2005).

17 Schultz, Teodoro (1973). 
isso não significou a garantia de um salário mínimo, nem boas condições de trabalho e, nem tampouco, a instabilidade no emprego: suas trajetórias de trabalho se inscreviam na impermanência e na flexibilidade, conforme já evidenciado por Silva (2009).

É possível constatar que, logo após o término das aulas que frequentaram o projeto Consórcio da Juventude os jovens estavam no ensino superior ou buscaram uma vaga na universidade. No entanto, também é verdade que o interesse por esse grau de ensino é impelido, sobretudo, pela crença de que com ele se consiga agora um "trabalho digno". Assim, mais uma vez, a educação é convocada não só para resolver o problema do desemprego juvenil frente ao exército de desempregados, mas, sobretudo, para conseguir um trabalho estável que lhe possibilite condições melhores de vida.

O Ensino Superior se configurou para os jovens e seus familiares mais uma estratégia para galgar um "melhor emprego", um investimento que demandou - assim como na escola e no Consórcio Social da Juventude - esforços pessoais e familiares. As trajetórias dos jovens na busca por uma vaga no ensino superior expressam as relações entre a educação e as relações sociais de classe. As transições dos jovens do ensino médio à universidade evidenciam as desigualdades presentes na sociedade e as dificuldades de acesso que os jovens pobres têm ao procurarem um espaço no ensino superior.

Assim, foi possível observar que os percursos analisados informam três tendências que expressam a manutenção das desigualdades nas relações de produção, cujo resultado será a perpetuação da desigualdade em todos os âmbitos: jovens oriundos da escola pública que se percebem em condições desiguais de acesso e, por isso, nem mesmo almejam a universidade pública; jovens trabalhadores que, mesmo desejando o ensino público, não buscam sua inserção porque alguns cursos são oferecidos em tempo integral, impedindo-os de conciliar jornadas de trabalho com jornadas de estudo e; jovens que, mesmo reconhecendo suas "deficiências" 18 de conteúdos demandados nos exames de acesso ao ensino superior público, investem em sua formação por meio de cursinhos comunitários, e prestam inúmeros vestibulares nas universidades públicas e não obtém resultados positivos.

Qual foi o destino desses jovens? Seis dos nove pesquisados estão na universidade e três estão em processo seletivo. O grupo que conseguiu se inserir no ensino superior está em instituições privadas19. Destes, cinco são bolsistas do ProUni, estão no ensino superior privado a distancia, e cursam graduações no campo da educação. Essas trajetórias apontam

18 Como destacou Ana Paula.

19 A jovem Iranildes Paula, em 2010, já havia concluído seu curso de licenciatura em Letras. 
para um movimento na política de expansão do ensino superior brasileiro20 para juventude trabalhadora brasileira: expansão do ensino superior, por meio de cursos pagos a distancia inscritos, especialmente, no campo da educação. Trata-se da forma "aligeirada" de formação, já analisada por Saviani (2008).

Pode-se concluir que a presente estratégia tende a cristalizar ainda mais a dinâmica de segmentação e diferenciação do sistema de formação para o sistema de emprego, destinando, primeiramente, as universidades academicamente superiores para aqueles que conseguem passar nos vestibulares das instituições públicas. Este grupo, como já bem demonstram outras pesquisas, é constituído por aqueles que tiveram condições de experienciar educação de qualidade; e as faculdades e centros universitários, academicamente mais fracos, para os pobres que agora conseguem, via ensino superior à distância, acessá-los.

\section{REFERÊNCIAS}

ALVES, N. Juventudes e Inserção Profissional. Educa-Unidade de I\&D de Ciências da Educação, 2008.

BALTAR, P. et al. Trabalho no Governo Lula: uma reflexão sobre a recente experiência brasileira. Carta social do Trabalho. Campinas, Centro de Estudos Sindicais e de Economia do Trabalho, n. 12, 2010.

BLOCH, Ernst. O Princípio Esperança. Vol. 1, Rio de Janeiro: Editora Contraponto/Ed. UFRJ, 2005

BOURDIEU, P. A Escola conservadora: as desigualdades frente à escola e à cultura. In: NOGUEIRA, M. A.; CATANI, A. (org.). Escritos de educação. Petrópolis, Vozes, p 39-64, 1998.

BOURDIEU, P; PASSERON, J.-C. Les héritiers: les étudiants et la culture. Paris: Les Éditions de Minuit, 1964.

CASTEL, R. As metamorfoses da questão social: uma crônica do salário. Tradução Iraci D. Poleti. Petrópolis, RJ: Vozes, 1998

CATANI, A. M.; HEY, A.P.; GILIOLI, R. de S. P. PROUNI: democratização do acesso às Instituições de Ensino Superior? Educ. rev., n. 28, dez. 2006. p.125-140.

CORBUCCI, P. R. et al. Situação Educacional dos Jovens Brasileiros. In: ANDRADE, C. C.; AQUINO, L. M. C.; CASTRO, J. A. (org.) Juventude e políticas sociais no Brasil. Brasília: Ipea, 2009. p. 91-108.

20 É importante destacar que na política de ampliação do ensino superior, implementada pelo Ministério da Educação, outras estratégias são adotadas, conforme já foi destacado no terceiro capítulo deste trabalho. 
ELIAS, N; SCOTSON, J. L. Os estabelecidos e os outsiders: sociologia das relações de poder a partit de uma pequena comunidade. Tradução Vera Ribeiro. Tradução do posfácio à edição alemã, Pedro Süssekind. Apresentação e revisão técnica, Federico Neiburg. Rio de Janeiro: Jorge Zahar Ed.; 2000.

FRIEDMAN, M; FRIEDMAN, R. Liberdade de escolher. Tradução Ruy Jungman. Rio de Janeiro: Record,1987.

FRIGOTTO, G. A produtividade da escola improdutiva. São Paulo: Cortez, 2001.

FRIGOTTO, G. Educação para a "Inclusão" e a "Empregabilidade": Promessas que Obscurecem a realidade. In: CANÁRIO, R.; RUMMERT, S. M. (org.). Mundos dos Trabalho e Aprendizagem. Lisboa: Educa|Autores, 2009. p. 61-77.

INSTITUTO INTERNACIONAL PARA A EDUCAÇÃO SUPERIOR NA AMÉRICA LATINA E CARIBE (IESALC); ORGANIZAÇÃO DAS NAÇÕES UNIDAS PARA A EDUCAÇÃO, A CIÊNCIA E A CULTURA (UNESCO). Informe sobre la educación superior en América Latina y el Caribe 2000-2005: la metamorfosis de la educación superior. Caracas: Editorial Metrópolis, 2006.

LEDRUT, R. Sociologie du Chômage. Presses Universitaires de France, Paris, 1966.

PAIS, J. M. Ganhos, tachos e biscates: Jovens, trabalho e futuro. Lisboa: Ambar, 2005.

POCHMANN, M. A batalha pelo primeiro emprego: a situação atual e as perspectivas do jovem no mercado de trabalho. 2 ed. São Paulo: Publisher Brasil, 2007.

POCHMANN, M. Pedagogia da inclusão. Revista Ensino Superior, São Paulo, n. 96, 2006. p. 1-7.

SEGNINI, L. P. R. Educação, trabalho e desenvolvimento: uma complexa relação. Trabalho \& Educação, Belo Horizonte, v. 6, 2000. p. 14-47.

SILVA, J. H. da. Os Filhos do desemprego: Jovens Itinerantes do Primeiro Emprego, Brasília: Liber livro, 2009

SILVA, J. H. da. Juventude Trabalhadora Brasileira: Percursos Laborais, Trabalhos Precários e Futuros (In)certos. UNICAMP, 2012. Tese (Doutorado em Educação ) Universidade Estadual de Campinas , Campinas, 2012. 


\section{SOBRE OS AUTORES:}

\section{José Humberto da Silva}

Doutor em Educação pela Universidade Estadual de Campinas ( Unicamp). Professor Titular da Universidade do Estado da Bahia (UNEB), Campus I(DEDC). Professor permanente do Programa de Pós-Graduação em Educação de Jovens e Adultos ( MPEJA). Líder do grupo de Pesquisa FORTIS ( Formação Trabalho e Identidades) e pesquisador do Grupo de Estudos e Pesquisa em Educação e Diferenciação Sócio-Cultural (Unicamp). Coordenou inúmeros projetos no campo da Juventude-Educação- Trabalho, a exemplo “ Da profissionalização à inserção no mercado de trabalho?", financiado pela Secretaria de Educação do Estado da Bahia ( 2013-2017). Participou como pesquisador do Projeto "Organização e Condições do Trabalho Moderno. Emprego, Desemprego e Precarização do Trabalho”. Programa CAPESCOFECUB. Acordo Capes-Cofecub - UNICAMP/GTM/CNRS. E-mail:jhsilva@uneb.br/ zeuneb@hotmail.com /

\section{(iD http://orcid.org/0000-0002-7437-7017}

\section{Liliana Rolfsen Petrilli Segnini}

Pós-Doutorado em Genre et Rapports Sociaux -IRESCO-CNRS, GERS-IRESCO-CNRS, França. Livre Docente pelo Departamento de Ciências Sociais na Educação da Faculdade de Educação da Unicamp. Professora Titular da Universidade Estadual de Campinas - Unicamp (desde 2001). Professora e pesquisadora plena da Faculdade de Educação da Unicamp; professora e pesquisadora colaboradora do programa de Doutorado em Ciências Sociais, do Instituto de Filosofia e Ciências Humanas (IFCH) da Unicamp. Coordenou o Projeto de Cooperação Internacional CNRS/FAPESP "Qual é o sentido social da modernização no trabalho"(2006/2009). Pesquisadora Associada - Centre de Recherches Sociologiques et Politiques de Paris (CRESPPA, UMR 7217), equipe Genre Travail Mobilités (GTM). Membro do Acordo de Cooperação Internacional Capes Cofecub "Organização e condições de trabalho moderno: emprego, desemprego e precarização do trabalho" (2010/2014). Membro do Acordo Capes Cofecub "O sentido das mudanças e mudanças de sentido" (2015/2019). Membro da diretoria da ALAST - Associação Latinoamericana de Sociologia do Trabalho (2012/2013). Membro da diretoria da ABET - Associação Brasileira de Estudos do Trabalho. Membro do Reseau Genre et Migrations, França. Membro da rede Remir Trabalho. Pesquisadora CNPq 1 B. Projeto em desenvolvimento (2019/2022): Migrações internacionais e reforma trabalhista - Implicações para o trabalho artístico numa perspectiva comparativa internacional Pesquisa em andamento. e-mail: lilianaseg@uol.com

(iD) http://orcid.org/0000-0002-0916-6969 